\title{
Human Milk-Based Industry in the Muslim World: Religioethical Challenges
}

\author{
Mohammed Ghaly
}

$\mathbf{H}$ UMAN MILK BANKS have been established in $>35$ countries worldwide; however, there are currently no human milk banks in the Islamic countries. The Islamic tradition recognizes breast milk as the optimal source of nutrition for infants, yet religioethical reservations have prevented the establishment of a human milk-based industry in Muslim countries. ${ }^{1}$ In Islamic law, breastfeeding establishes a kinship (i.e., milk kinship) between the mother or wet nurse and the recipient of the milk. The milk kinship prohibits marriage; a man cannot marry the woman who breastfed him and certain of her relatives (e.g., mother, sisters, and daughters). There are, however, requirements for establishing a milk kinship, and they all revolve around three main aspects: (1) the wet nurse, (2) the milk, and (3) the nursling (Fig. 1). The identity of the wet nurse must be known so as to prevent improper marriage. The breast milk must reach the baby's stomach; however, there is a difference of opinion in whether the milk must be suckled directly from a breast or whether it can be delivered through alternative means (e.g., bottle and feeding tube). There is also discussion over what quantity of milk and how many breastfeeding sessions constitute a milk kinship. Lastly, the nursling (i.e., infant) should not be older than 2 years.

The concept of human milk banking poses a new question for contemporary religious scholars_-does using milk from banks create a kinship with the donors? The issue of milk banks has been evaluated by contemporary institutions established to address new religious and scientific issues relevant to the Muslim world (e.g., Islamic Organization for Medical Sciences [IOMS], Islamic Fiqh Academy [IFA], and International Islamic Figh Academy [IIFA]). These institutions have released their own nonbinding guidelines (fatwas) that are either for (unproblematic) or against (problematic) the establishment of milk banks (Fig. 2).

Muslims supporting the unproblematic position do not believe that milk banks are not equal to breastfeeding and consider the use of milk banks and donation of milk a noble deed. This reasoning is based on three arguments: (1) the verse in the Quran defining milk kinship refers to "... your mothers who have suckled you..." Motherhood is not just based on the consumption of milk, but also the closeness and attachment that results from being in direct contact with the mother's breast. Babies receiving donor milk are not suckled by the donor mothers. (2) The identities of the milk donors and the total amount of milk donated are not known; thus, no milk kinship can be established. (3) In response to controversial issues, especially public affairs, Islam tends to adopt the more lenient approach, which, in this case, would be allowing the establishment of milk banks.

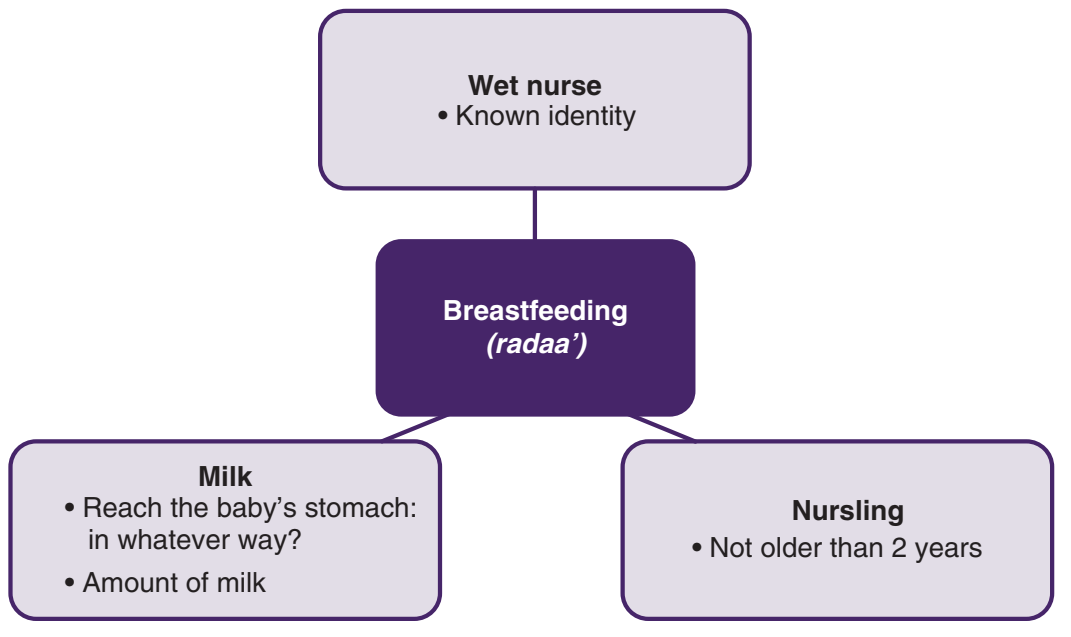

FIG. 1. Requirements for establishing a milk kinship.

Professor of Islam and Biomedical Ethics, Research Center for Islamic Legislation and Ethics (CILE), College of Islamic Studies, Hamad Bin Khalifa University, Doha, Qatar.

This article is based on a presentation given at the 5th International Conference on Human Milk Science and Innovation (ICHMSI), Pasadena, California, September 6-8, 2017. 

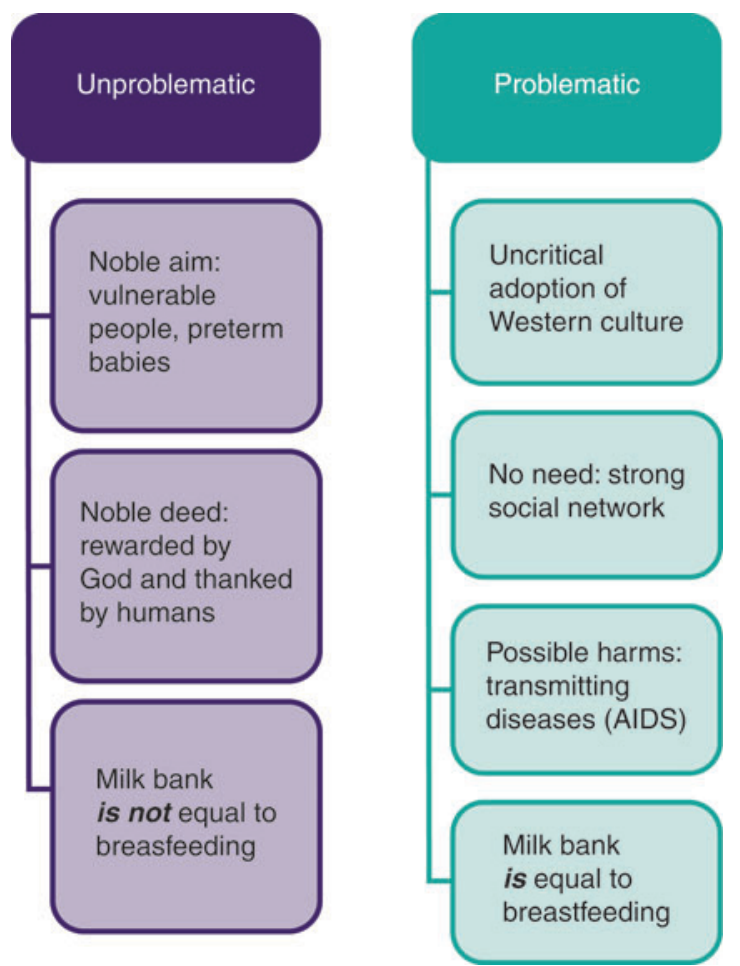

FIG. 2. Differing positions on human milk banks in the Muslim world.

In contrast, supporters of the problematic position consider milk banks as equal to breastfeeding and believe they are unnecessary in the Muslim world, where strong social networks make it easier to obtain milk, if needed. In response to the three arguments already outlined, opponents of milk banks (1) reject a literalist approach to interpreting the Quran and believe that the transmission of milk by any means (e.g., suckling, bottle, and tube) constitutes a milk kinship. (2) Since the identity of the donors is unknown and amount of milk donated creates uncertainty, milk banks should not be introduced in the first place. In other words, the advocates of this position explained, the unknown identity of the wet nurse and the unknown amount of milk should be seen as problems for which milk banks should not be established, not to be used as arguments for holding that milk banks do not establish milk kinship. (3) Based on a Prophetic tradition, a more cautious approach should be taken (i.e., prohibition of milk banks).

Strategies to establish a human milk-based industry in the Muslim world must keep in mind the best interests of infants and children while respecting the tradition of milk kinship. One possible option is to have milk banks establish a milk kinship with the donors; milk from just three to five donors would be given to a baby, and the identity of the donors would be made available. Another possibility would be to maximize the number of donors (e.g., 50-200) so that a baby would receive no more than four feeding sessions from a single donor, thus preventing a milk kinship from forming. More research on the technicalities of Islamic discourse, how reality will change discourse (e.g., survival of preterm infants), and the perception of individuals (mothers, family members, etc.) is needed to help overcome the religious and cultural obstacles to establishing milk banks in the Muslim world.

\section{Acknowledgments}

I would like to thank Alan Lucas and all organizers for their kind invitation to participate in this conference.

\section{Reference}

1. Ghaly M. Milk banks through the lens of Muslim scholars: One text in two contexts. Bioethics 2012;26:117-127.

Address correspondence to: Mohammed Ghaly, PhD

College of Islamic Studies

Hamad Bin Khalifa University

P.O. Box 34110

Education City

Doha

Qatar

E-mail: mghaly@hbku.edu.qa 